\title{
Observaciones al Microscopio Electrónico de Barrido del Interior de un Proglótido de un Parásito Adulto de Taenia solium
}

\author{
Scanning Electron Microscopy Observations of the \\ Cross-Section of a Taenia solium Adult Tapeworm \\ ***Javier R. Ambrosio; "Armando Zepeda-Rodríguez; **Araceli Ferrer; \\ ** Olivia Reynoso-Ducoing \& *Teresa I. Fortoul
}

\begin{abstract}
AMBROSIO, J. R.; ZEPEDA-RODRIGUEZ, A.; FERRER, A.; REYNOSO-DUCOING, O. \& FORTOUL, T. I. Scanning electron microscopy observations of the cross-section of a Taenia solium adult tapeworm. Int. J. Morphol., 29(1):127-132, 2011.

RESUMEN: No existen, hasta el momento, imágenes que muestren la disposición de la citoarquitectura de parásitos adultos de Taenia solium, parásitos los cuales se encuentran en el intestino de portadores humanos asintomáticos. Las causas de ello podrían tener como base el que cuando se recuperan los parásitos, ellos han sufrido alteraciones debidas a la respuesta inmune de sus hospederos o bien, por el efecto que han producido en los parásitos los fármacos antihelmínticos que hayan sido usados en el tratamiento de los pacientes. Una de las alternativas que se han encontrado para la obtención de parásitos adultos, es la obtención de tenias a partir del modelo de teniosis experimental en hámsteres dorados e inmunosuprimidos y que gracias a este modelo se han podido efectuar diferentes tipos de estudios de los parásitos de esta fase infectiva. El propósito de este reporte es presentar imágenes de ultraestructura, obtenidas mediante Microscopía Electrónica de Barrido, de un corte transversal obtenido de un proglótido de una tenia recuperada de una infección experimental. Las imágenes se obtuvieron a diferentes aumentos y muestran aspectos relacionados con la superficie tegumentaria, el tegumento sincicial continuo, la capa germinal que incluye el soma de algunas células subtegumentarias y los ductos del sistema protonefridial tanto vacíos como llenos con corpúsculos calcáreos. Las imágenes ultraestructurales obtenidas muestran una forma de observación de la anatomía microscopica de los parásitos en estudio y ello contribuye a ampliar el conocimiento de los mismos en relación a aspectos de su biología celular y su fisiología.
\end{abstract}

PALABRAS ClAVE: Taenia solium; Cestodos; Cisticercos; Gusanos planos; Microscopía Electrónica de Barrido; Microvellosidades; Tegumento; Proglótido; Sistema protonofridial; Cisticercosis: Teniosis.

\section{INTRODUCCIÓN}

Un parásito adulto de T. solium es gusano plano que cuando infecta el intestino de una persona, alcanza hasta los 4 metros de longitud y vive anclado, mediante su doble corona de ganchos y sus ventosas, dentro del lumen intestinal. La teniosis es una enfermedad intestinal producida por un solo gusano adulto y la cual es una enfermedad asintomática considerada importante en la salud pública de personas que viven en regiones endémicas o hiperendémicas de países en desarrollo (Flisser, 2006; Pawlowski et al., 2005). La enfermedad se desarrolla luego de la ingestión accidental de cisticercos (las formas larvarias de T. solium), los cuales pueden estar contenidos en carne de cerdo infectada y mal cocinada. Dentro del tracto digestivo, los cisticercos sufren un fenómeno de evaginación debido al microambiente intestinal en el que se encuentren (Pawlowski et al.). La infección se presenta cuando la tenia naciente se fija firmemente al intestino mediante su escólex, el cual es del tamaño de la ojiva de una aguja y que está formado de una corona de ganchos, cuatro ventosas y un cuello. Luego, debido a la arquitectura de este segmento de la tenia y a la fortaleza que despliega durante su interacción con el intestino, el gusano puede crecer indefinidamente; si a un portador asintomático no se le trata adecuadamente con los fármacos antihelmínticos de elección, esta región permite que el parásito intestinal vuelva a recuperar su tamaño luego de 3 meses de haber

\footnotetext{
* Departamento de Biología Celular y Tisular. Facultad de Medicina, Universidad Nacional Autónoma de México (UNAM), México.

** Departamento de Microbiología y Parasitología. Facultad de Medicina, Universidad Nacional Autónoma de México (UNAM), México.
} 
sufrido el tratamiento. La otra región del gusano, en donde se encuentran los órganos especializados para la sobrevivencia, la división y la infección que produce el parasito, se le conoce como cadena estrobilar o estróbilo y contienen miles de segmentos conocidos como proglótidos, los cuales pueden ser inmaduros o maduros. En el caso de los proglótidos maduros, los cuales se encuentran situados en la porción final de la cadena estrobilar, contienen miles de huevos que pueden ser expulsados en la material fecal de las personas infectadas y que ello es la razón principal por la que, cuando son ingeridos por cerdos o de manera accidental por falta de higiene adecuada en los seres humanos, producen la cisticercosis. Luego, bajo las condiciones microambientales intestinales, los huevos eclosionan y se desarrollan hasta cisticercos que se alojan tanto en los músculos como en el cerebro de las personas que resulten infectadas. La presencia de cisticercos en el sistema nervioso central de las personas infectadas les produce la neurocisticercosis, la cual es una enfermedad que genera convulsiones de aparición repentina, tratamientos médicos costosos y de larga duración y la inhabilitación de las personas económicamente activas.

No hay posibilidades de efectuar estudios en tenias intactas que hayan sido recuperadas de infecciones naturales. Ello se debe a que los parásitos siempre resultan alterados por los daños de los tratamientos antihelmínticos y, por lo consiguiente, no es posible asegurar que las observaciones microscópicas de ellos sean las mas precisas y certeras (Willms et al., 2003). Sin embargo, es posible la recuperación de gusanos parásitos vivos, completos y pequeños desde las infecciones experimentales de hamsters dorados e inmunosuprimidos (Avila et al., 2006), con los cuales se pueden efectuar estudios a nivel de la interfase huésped-parásito, de la respuesta inmune tanto local como sistémica (Avila et al., 2002), así como de la expresión de proteínas musculares de los parásitos (Ambrosio et al., 1997; Gonzalez-Malerva et al., 2004).

A nivel ultraestructural, mediante la microscopía electrónica de transmisión (MET), se ha demostrado que los tejidos de las tenias están constituidas por varias capas; en la superficie, se encuentran una gran cantidad de microvellosidades que aparentan un ribete de cepillo y a través del cual se realiza una eficiente captura tanto de nutrientes como de macromoléculas provenientes de sus hospederos (Smyth \& McManus, 1989; Slais, 1970). Luego, en las capas parenquimatosas mas internas, se encuentran las células germinales tales como las correspondientes al sistema muscular de los gusanos, similares a las encontradas como parte del sistema de músculo liso del intestino de los vertebrados (Willms et al.), células subtegumentarias y flama, las cuales son consideradas como las subunidades del sistema protonefridial (Smyth \& McManus). A lo largo de las tenias, las capas mencionadas se presentan de tal manera que permiten que los parásitos se adapten de manera adecuada al intestino de su hospedero, como el caso de las microvellosidades de la tenia que compiten de manera eficiente con las microvellosidades intestinales y lo cual favorece que tengan una mayor capacidad de absorción de nutrientes.

Debido a la ventaja que representó la obtención de una tenia recuperada de una infección experimental de teniosis en un hámster, así como a la fractura accidental del parásito a nivel de su cadena estrobilar, el propósito de este trabajo es mostrar la morfología ultraestructural de las diferentes capas tisulares de la tenia mediante imágenes obtenidas por microscopía electrónica de barrido (MEB) bajo diferentes aumentos.

\section{MATERIAL Y MÉTODO}

Un hámster Mesocricetus auratus se infectó experimentalmente con la administración oral de 10 cisticercos obtenidos de carne de cerdo infectada de manera natural y de esta infección resultaron cinco tenias. Con la finalidad de evitar infecciones intestinales con otros parásitos helmintos, el hámster se trató previamente durante 5 días con $40 \mathrm{mg} / \mathrm{kg}$ of albendazol (Smith Klaine Beecham, México) y, al inicio de la infección, se indujo su inmunosupresión, la cual se mantuvo con dos dosis de $2 \mathrm{mg} / 100 \mathrm{~g}$ de peso de metil-prednisolona (Depomedrol, Merck). Luego de un mes de infectado, el animal se sacrificó bajo anestesia, bajo la Norma Oficial Mexicana para el manejo de animales (NOM062-ZOO-1999 de sacrificio de animales) bajo las condiciones aprobadas por el comité de ética de la Facultad de Medicina. Las tenias recuperadas del intestino del hámster infectado se encontraron vivas y presentaron movimientos vigorosos de sus cadenas estrobilares, los cuales se acompañaban de contracciones y relajación continuas. Luego de recuperados, los parásitos se lavaron completamente con solución salina fisiológica a $\mathrm{pH} 7.2$ at $4^{\circ} \mathrm{C}$ y su procesamiento, para su observación por MEB, como se hizo como lo descrito para adultos de Fasciola hepatica (Rivera et al., 2004), mediante el empleo de un equipo DSM-950 Zeiss bajo condiciones de $25 \mathrm{kV}$. Las observaciones se enfocaron hacia las zonas interiores de la sección transversal, la cual se localizó en aproximadamente $4 \mathrm{~mm}$ de longitud de la cadena estrobilar, medida desde la porción cefálica. Las fotografías obtenidas se digitalizaron en un escáner HP LaserJet 3050 Scanner 3060 y se editaron, para mejorar su contraste y brillo, mediante el programa de cómputo Adobe Photoshop V. 7.0. 


\section{RESULTADOS Y DISCUSIÓN}

La Figura 1 muestra varias imágenes del interior de un proglótido, las cuales se obtuvieron a diferentes aumentos. En A, el parasito intestinal se presenta completo con su porción cefálica que contiene su corona de ganchos, un par de ventosas, su cuello y una larga cadena estrobilar que presenta varios segmentos. La porción final de la cadena estrobilar se presenta aplastada debido a la manipulación que se hizo de la tenia durante su fijación. En la misma imagen, hacia la porción final indicada, se observa (dentro de un cuadro que lo señala) una zona de la cadena estrobilar que sufrió una fractura precisa entre dos proglótidos. En la observación a mayor aumento, del interior de uno de los proglótidos seccionados, destaca el tegumento sincicial con- tinuo que limita al proglótido y que se presenta como una envoltura externa. Hacia el interior del proglótido, por debajo de la envoltura indicada, el tejido parenquimatoso se presenta con una consistencia esponjosa. En C, a un aumento mayor con respecto lo presentado en $\mathrm{B}$, se muestra que la composición del proglótido tiene cuatro zonas: La más externa, correspondiente a la superficie de la envoltura, el borde exterior del proglótido, se presenta con la superficie semejante al ribete de un cepillo; sitio en el que se observan una gran cantidad de micrótricas. Luego, hacia el interior del proglótido, destaca una capa compacta y densa de tegumento sincicial continuo de aproximadamente $5 \mu \mathrm{m}$ de grosor. Mas hacia el interior, por debajo del tegumento sincicial,
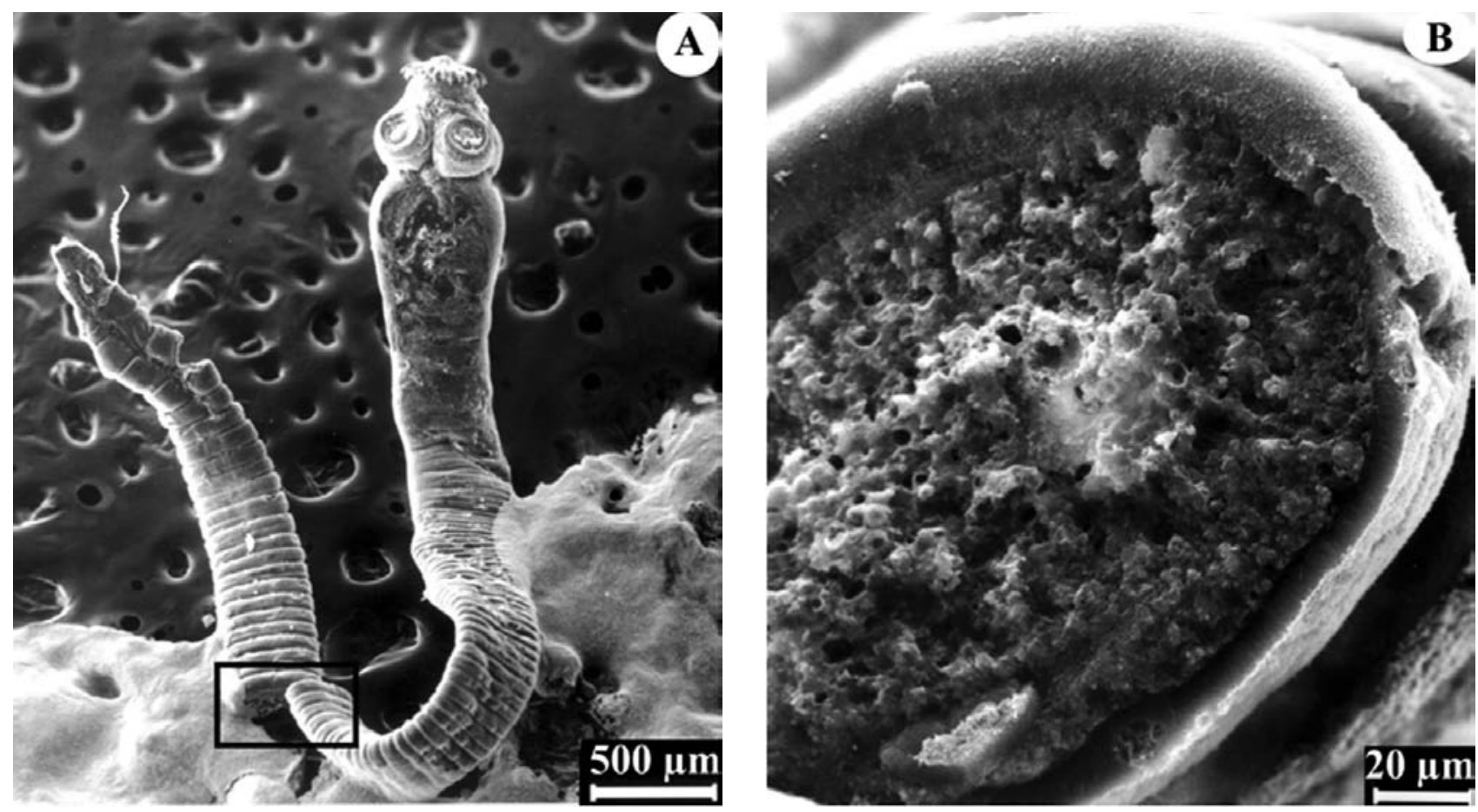

Fig. 1. Citoarquitectura de una sección transversal de un proglótido de una tenia de T. solium. Las imágenes se presentan en orden creciente de observación, que va desde la tenia entera hasta el parénquima en donde se destacan los ductos protonefridiales y los cuerpos celulares incrustados. Las imágenes (B, C, D, E y F) se obtuvieron del sitio (indicado con un cuadro en A) en donde la cadena estrobilar sufrió una fractura accidental luego de intentar pegar al parásito adulto al portamuestras para su observación microscópica. En A, la tenia se presenta con su porción cefálica coronada por ganchos y dos ventosas abiertas, su cuello no segmentado y una porción de su cadena estrobilar. En B, en la región media del proglótido fracturado, el tejido parenquimatoso interior parece esponjoso y está limitado por una cubierta. En C, grandes cantidades de microvellosidades se encuentran en la superficie del proglótido, mientras que la capa sincicial continua se conecta mediante puentes citoplasmáticos hacia el tejido parenquimatoso. Varios ductos protonefridiales se observan abiertos y vacíos; otros se encuentran con corpúsculos calcáreos en su interior. En D, las microvellosidades del ribete de cepillo se presentan claras y se observa que se asocian con la capa sincicial. En esta capa, una aparente terminación de un ducto protonefridial, se presenta como una invaginación de la membrana basal. E and $\mathrm{F}$ muestran dos amplificaciones del parénquima tisular en donde destacan los ductos protonefridiales, los cuerpos celulares y el aspecto esponjoso del parénquima. En E se presenta una vista lateral del parénquima en donde sobresale un cuerpo cellular y en F, correspondiente a la misma región de $\mathrm{E}$, se observan ductos protonefridiales abiertos y, en algunos casos, con contenidos internos de corpúsculos calcáreos. Los aumentos originales por el MEB fueron: 25x (A), 500x (B), 1000x (C) y 5000x (D-F). Las distancias de trabajo fueron de 15, 19, 16, 20, 17 and $15 \mathrm{~mm}$. 

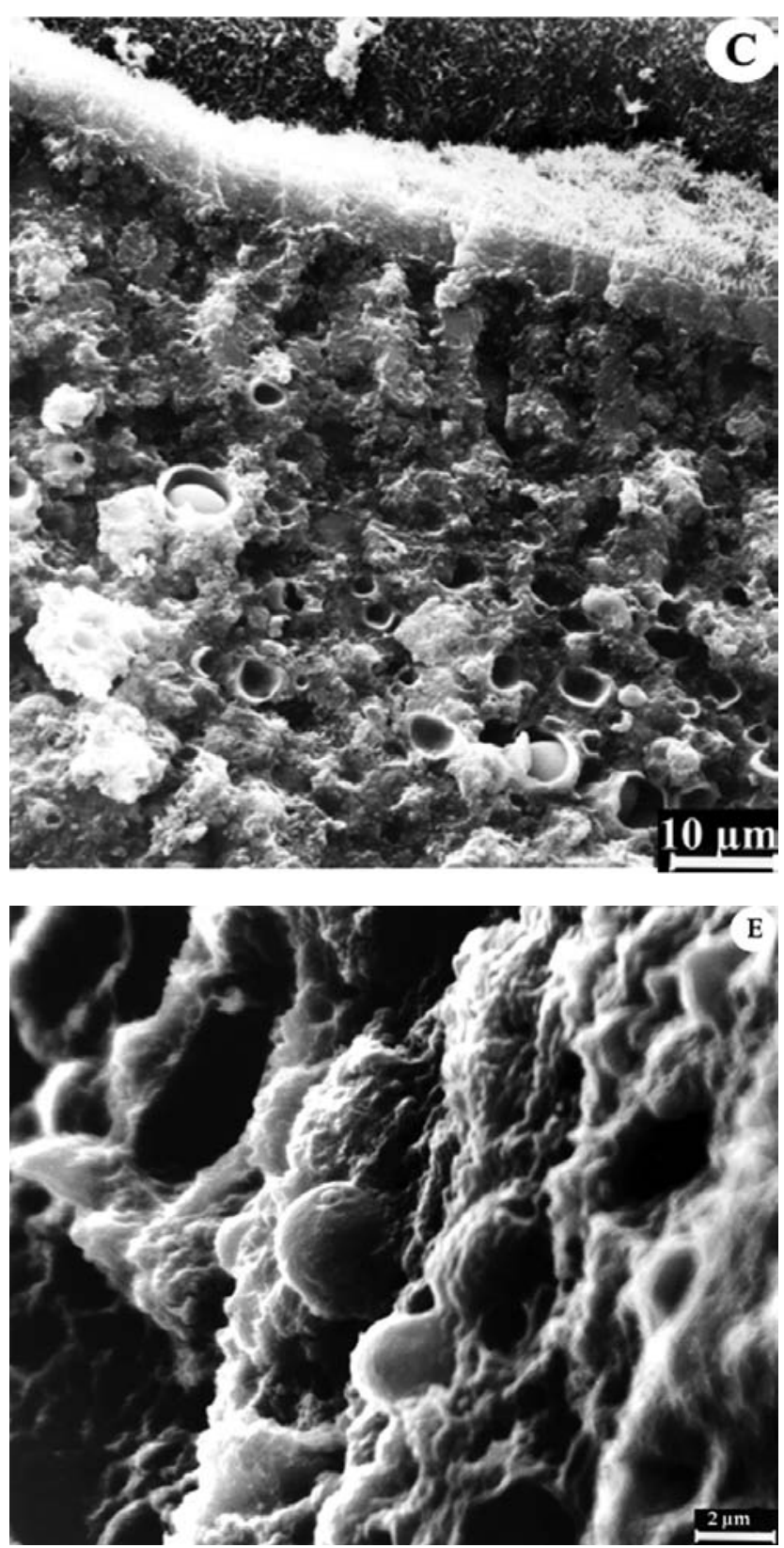

se observan extensiones citoplasmáticas tegumentarias que aparentemente van (o vienen) de la superficie interior de tal sincicio hacia el parénquima esponjoso. Mas hacia el interior del proglótido, en la zona del parénquima tisular de apariencia esponjosa, se observan varias estructuras tubulares segmentadas transversalmente de diferentes tamaños, que en algunos casos parecen tener un borde definido y en otros no. En el caso de algunas de borde definido, hacia su interior, se encuentran que contienen estructuras ovoides densas de aproximadamente $6 \mu \mathrm{m}$ de diámetro similares a las descritas mediante MET por Vargas-Parada et al. (1999) y que presumiblemente podrían corresponder a los denomi-
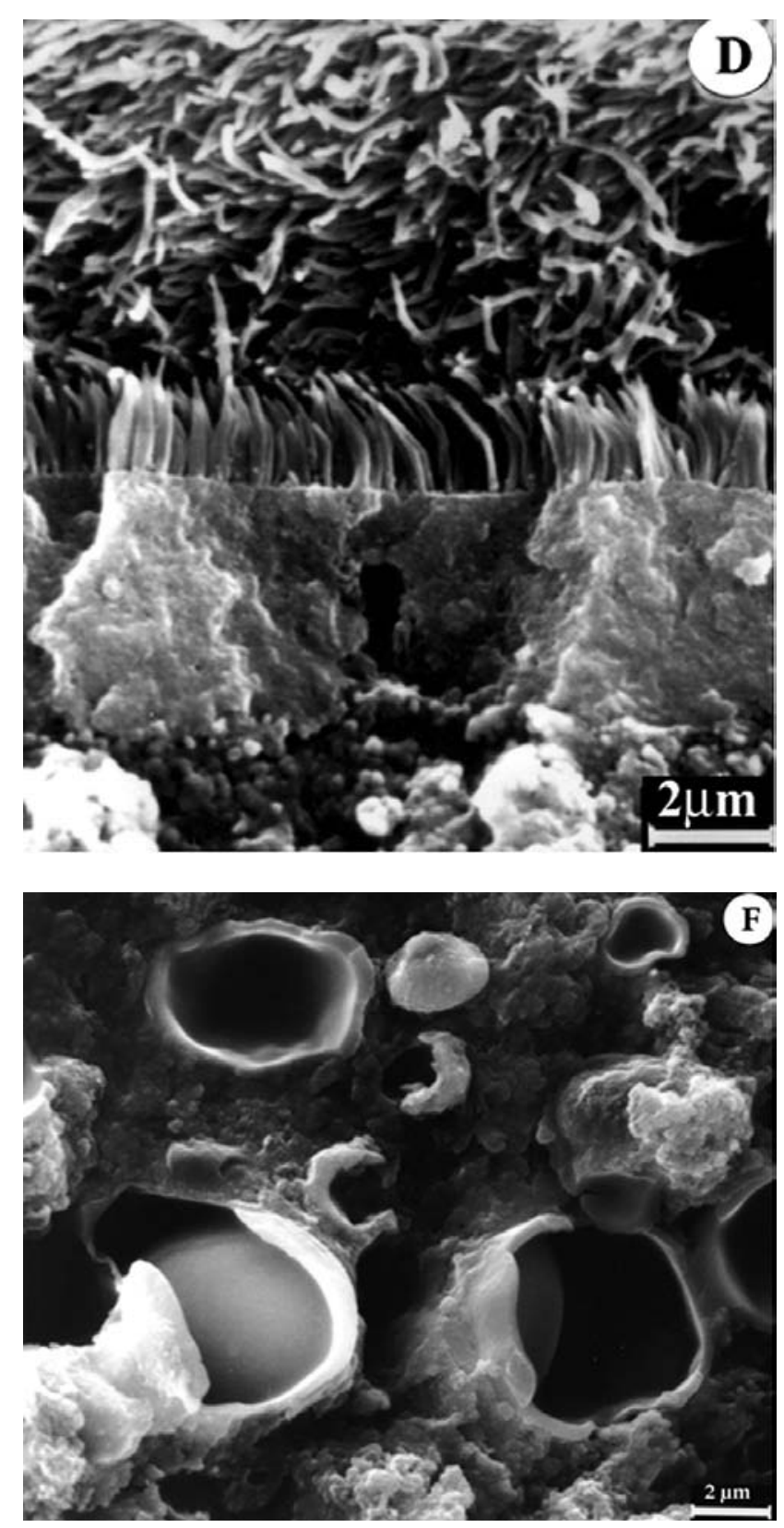

nados corpúsculos calcáreos. Por lo consiguiente, por su contenido, su diámetro y orientación, estas estructuras tubulares podrían formar parte de los ductos del sistema protonefridial (DSP). En esta región parenquimatosa, que corresponde a la matriz intersticial, se observan varios cuerpos celulares incrustados y los cuales, en algunos casos, parecen estar muy cerca de los ductos protonefridiales. En la imagen $\mathrm{D}$, la cual corresponde a un aumento de 5000x de la imagen $\mathrm{C}$, se observa como toda la superficie tegumentaria está completamente cubierta de microvellosidades, las cuales tienen una forma característica en la que su punta es mas delgada que su base y lo cual coteja con la morfología que 
se considera típica para los cestodos (Lumsden \& Hildreth, 1983). En lo referente a la capa tegumentaria, ésta se presentó como continua en todo el recorrido microscópico que se efectúo a lo largo de la envoltura del proglótido en observación. Sin embargo, como se muestra en la figura $\mathrm{D}$, la continuidad que presenta se llega a distorsionar por alguna invaginación de lo que podría corresponder a la membrana basal del tegumento; cabría la posibilidad de que dicho tipo de invaginaciones sean conexiones que permitan el que los DSP se proyecten hacia el exterior del proglótido del parásito de forma semejante a lo descrito para los organismos monogeneos (Rohde et al., 1992), pero que en este tipo de observaciones no se lograron visualizar completamente. No es posible con las observaciones obtenidas el establecer si los ductos protonefridiales llegan hasta la superficie de los parásitos y lo cual aún sigue siendo un tema de debate para los cestodos; sin embargo, según lo que se ha observado con cisticercos vivos, parece que existe la apertura de poros en la superficie de los parásitos (Voge, 1963). De ser así, cabría la posibilidad de que estos fueran muy dinámicos y no se ha encontrado el momento adecuado para su visualización en fase de apertura a través del tegumento sincicial continuo. Las características de la gran dinámica de reestructuración del tegumento, dado que es en esta capa en donde se lleva a cabo un tráfico vesicular continuo para el transporte de macromoléculas (Ambrosio et al., 1994), permitirían que esta región parasitaria tenga una gran capacidad de continua regeneración. Sin embargo, según la misma imagen $\mathrm{D}$, podría darse otra posibilidad para que los cestodos eliminen lo que ya no requieran y que ello se deba a que los poros podrían no abrirse en la superficie, sino que terminen en el citoplasma distal del tegumento, cerca de la membrana basal del tegumento como se ha demostrado para el organismo monogeneo Anoplodiscus cirrusspiralis (Rohde et al.). Con base a ello, parece que la conexión entre el tegumento sincicial y la superficie de los parasitos, requerida para la eliminación o secreción de sustancias, debe estar asociada a los eventos de tráfico vesicular semejantes al fenómeno de exocitosis. Como se ha mencionado, el tegumento de los cestodos está constituido por una gran cantidad de microvesículas que se supone están en continuo movimiento y que participan también en la internalización de macromoléculas de este tipo de organismos como lo demostrado para cisticercos de T. crassiceps (Ambrosio et al., 1994). Estas suposiciones de cómo es que los cestodos podrían eliminar sus desechos aun permanecen presentes, ya que este tipo de parásitos no cuentan con un sistema digestivo como lo presentan los trematodos y los nematodos. En las imágenes $\mathrm{E}$ and $\mathrm{F}$ se muestran amplificaciones del parénquima, las cuales se observan de perfil (E) y de frente al lector (F). En el primer caso (E) se observa, en primer plano, como emerge un cuerpo celular y como la matriz intersticial pierde su continuidad por la presencia de un ducto protonefridial abierto. En el segundo caso (F), correspondiente a la misma zona observada en E, se observa que el cuerpo celular está cerca de un ducto protonefridial abierto en el que no hay contenido alguno, pero que en el interior de otros dos ductos (de mayor diámetro y por debajo del que se encuentra sin contenido) hay corpúsculos calcáreos. El cuerpo celular mencionado, debido a su cercanía con el DSP podría corresponder a la porción del soma de una célula flama de manera semejante a lo que se descrito en observaciones, mediante MET, en relación a sistemas protonefridiales de ténidos. La consistencia de la matriz intersticial (como se muestra en las figuras B, C, D y F) permite darse una idea de que la constitución esponjosa del parénquima de los proglótidos es suave, flexible y ello está asociado con los movimientos continuos de contracción y relajación que efectúan los proglótidos cuando se mueven en el conjunto de cómo lo hace la cadena estrobilar. En conclusión, las imágenes presentadas aquí mediante el empleo de la MEB muestran aspectos tridimensionales de la forma en que están constituidas las estructuras internas de los proglótidos de tenias recuperadas de infecciones experimentales. Estas observaciones microscópicas contribuyen a ampliar el conocimiento de la estructura fina morfológica de parásitos adultos de ténidos, incluso de céstodos, y ofrecen apoyo adicional para la explicación de ciertos aspectos morfofisiológicos de estos gusanos y los cuales podrían ser vitales para su sobrevivencia en sus hospederos. Cabe recordar que estos organismos se han considerado como fábricas de biomasa porque cuentan con la capacidad de utilizar eficientemente los nutrientes de sus hospederos, tienen una gran capacidad de recuperarse ante un inadecuado tratamiento quimioterapeútico (Flisser) y se logran adaptar a las condiciones microambientales que imperan aún bajo grandes movimientos intestinales de sus hospederos.

AGRADECIMIENTOS: Lo realizado en este trabajo se ha apoyado de los recursos ofrecidos por apoyos financieros recibidos de DGAPA-UNAM IN216107; IN201510 y DGAPA-IXTLI 0709008.

AMBROSIO, J. R.; ZEPEDA-RODRIGUEZ, A.; FERRER, A.; REYNOSO-DUCOING, O. \& FORTOUL, T. I. Scanning Electron Microscopy observations of the cross-section of a Taenia solium adult tapeworm. Int. J. Morphol., 29(1):127-132, 2011.

SUMMARY: There are no clear morphological evidences of the cytoarchitecture of intestinal adult tapeworms of Taenia solium recovered from infected humans. Parasites could be altered because of the host's immunological response or by the direct action of drugs used for antihelminthic treatment. Experimental taeniosis in immunosuppressed golden hamsters is a useful way for recovering and studying adult parasites. The purpose of this report 
is to show images, taken at the ultrastructural level by Scanning Electron Microscopy (SEM), of a cross-sectioned strobilar chain from an adult tapeworm. The parasite was recovered from an experimental infection. Images were taken at several magnifications; they show the brush border tegumental surface, the syncytial tegument, the germinal layer, some cell bodies and the protonephridial system ducts: empty or filled with calcareous corpuscles. Ultrastructural images taken using SEM of T. solium adult parasites, recovered from experimental infections, could be a new way for observing the microscopic anatomy of these parasites and for increasing the knowledge of aspects related to their cellular biology and physiology.

KEY WORDS: Taenia solium; Cestoda; Cysticerci; Tapeworm; Scanning electron microscopy; Microvilli; Tegument; Proglottid; Protonephridial system.

\section{REFERENCIAS BIBLIOGRÁFICAS}

Ambrosio, J.; Landa, A.; Merchant, M. T. \& Laclette, J. P. Protein uptake by cysticerci of Taenia crassiceps. Arch. Med. Res., 25(3):325-30, 1994.

Ambrosio, J.; Cruz-Rivera, M.; Allan, J.; Morán, E.; Ersfeld, K. \& Flisser, A. Identification and partial characterization of a myosin-like protein from cysticerci and adults of Taenia solium using a monoclonal antibody. Parasitology, 114:545-53,1997.

Avila, G.; Aguilar, L.; Benitez, S.; Yepez-Mulia, L.; Lavenat, I. \& Flisser, A. Inflammatory responses in the intestinal mucosa of gerbils and hamsters experimentally infected with the adult stage of Taenia solium. Int. J. Parasitol., 32(10):1301-8, 2002.

Avila, G.; Teran, N.; Aguilar-Vega, L.; Maravilla, P.; MataMiranda, P \& Flisser, A. Laboratory animal models for human Taenia solium. Parasitol. Int., 55 Suppl:S99S103, 2006.

Flisser, A. Where are the tapeworms? Parasitol Int., 55Suppl:S117-20, 2006.

Gonzalez-Malerva, L.; Cruz-Rivera, M.; Reynoso-Ducoing, O.; Retamal, C.; Flisser, A. \& Ambrosio, J. R. Muscular myosin isoforms of Taenia solium (Cestoda). Cell Biol. Int., 28(12):885-94, 2004.

Lumsden, R. D. \& Hildreth. M. B. The fine structure of adult tapeworms. In: Biology of the Eucestoda. Arme, C. \& Pappas, P. W. (Eds.) New York, Academic Press, 1983.
Pawlowski, Z.; Allan, J. \& Sarti, E. Control of Taenia solium taeniasis/cysticercosis: from research towards implementation. Int. J. Parasitol., 35(11-12):1221-32, 2005.

Rivera, N.; Ibarra, F.; Zepeda, A.; Fortoul, T.; Hernández, A.; Castillo, R. \& Cantó, G. Tegumental surface changes in adult Fasciola hepatica following treatment in vitro and in vivo with an experimental fasciolicide. Parasitol. Res., 93(4):283-6, 2004.

Rohde, K.; Watson, N. A. \& Roubal, F. Ultrastructure of the protonephridial system of Anoplodiscus cirrusspiralis (Monogenea Monopisthocotylea). Int. J. Parasitol., 22(4):443-57, 1992.

Smyth, J. D \& McManus, D. P. The adult cestode: special structural features relevant to its physiology. In: The physiology and biochemistry of cestodes. Cambridge, Cambridge University Press, 1989.

Slais, J. The morphology and pathogenicity of the bladder worms of Cysticercus cellulosae and Cysticercus bovis, Academia, Praga, 1970. p.144.

Vargas-Parada, L.; Merchant, M. T.; Willms, K. \& Laclette, J. P. Formation of calcareous corpuscles in the lumen of excretory canals of Taenia solium cysticerci. Parasitol. Res., 85(2):88-92, 1999.

Voge, M. Observations on the structure of cysticerci of Taenia solium and Taenia saginata (Cestoda: Taeniidae). J. Parasitol., 49:85-90, 1963.

Willms, K.; Robert, L. \& Caro, J. A. Ultrastructure of smooth muscle, gap junctions and glycogen distribution in Taenia solium tapeworms from experimentally infected hamsters. Parasitol. Res., 89(4):308-16, 2003.

Dirección para correspondencia:

Dr. Javier R. Ambrosio

Departamento de Microbiología y Parasitología Facultad de Medicina

Universidad Nacional Autónoma de México (UNAM)

Edificio A, 2do. Piso. Circuito Interior

Ciudad Universitaria 04510

Ciudad de México

MÉXICO

E-mail:jrah@servidor.unam.mx

Recibido : 28-06-2010

Aceptado: 16-11-2010 